\title{
A pilot investigation on DNA methylation modifications associated with complex posttraumatic symptoms in elderly traumatized in childhood
}

\author{
Zoya Marinova ${ }^{1}$, Andreas Maercker ${ }^{2 *}$, Edna Grünblatt ${ }^{1}$, Tomasz K. Wojdacz ${ }^{3}$ and Susanne Walitza ${ }^{1}$
}

\begin{abstract}
Objective: Complex posttraumatic stress disorder (CPTSD) is a newly proposed diagnosis in the International Classification of Diseases-version 11, which is currently intensively investigated. Childhood trauma is regarded as main source of CPTSD symptoms, even in later life. Induction of DNA methylation changes by childhood trauma may contribute to its long-lasting adverse health consequences. The current study analyzed the correlation of genome-wide DNA methylation profiles with complex posttraumatic sequelae in buccal epithelial cells from 31 elderly former indentured child laborers (Verdingkinder) using the Infinium Illumina 450k Human DNA methylation chip.

Results: DNA methylation modifications indicated experiment-wide significant associations with the following complex posttraumatic symptom domains: dissociation, tension reduction behavior and dysfunctional sexual behavior. Differentially methylated CpG sites were mapped to the genes huntington associated protein 1 (HAP1), RAN binding protein 2 (RANBP2) and proteasome subunit alpha 4 (PSMA4), respectively. In addition, the methylation of cg07225277 located in carnosine synthase 1 (CARNS1) correlated with trauma symptom complexity. Our pilot data suggest correlation of DNA methylation modifications with complex posttraumatic symptoms in elderly individuals subjected to prolonged and complex childhood trauma. More comprehensive and elaborated studies should be carried out to analyze epigenetic modifications associated with CPTSD.
\end{abstract}

Keywords: Childhood trauma, Complex posttraumatic stress disorder, DNA methylation, Epigenetic modifications

\section{Introduction}

Exposure to childhood adversities has been associated with increased risk for mental illness in later life, including posttraumatic stress disorder (PTSD) and complex posttraumatic stress disorder (CPTSD) [1, 2]. Symptoms characteristic of PTSD include re-experiencing the traumatic event, avoiding stimuli associated with it and hyperarousal. CPTSD according to the International Classification of Diseases-version 11 (ICD-11) incorporates in addition to the PTSD symptoms also

\footnotetext{
*Correspondence: maercker@psychologie.uzh.ch

2 Department of Psychology, Division of Psychopathology and Clinical Intervention, University of Zurich, Binzmühlerstrasse 14/17, Raum BIN 3 E 14, 8050 Zurich, Switzerland

Full list of author information is available at the end of the article
}

disturbances in other mental and behavioral symptom areas [3, 4]. A high number of different childhood traumatic events has been correlated to increased complexity of posttraumatic symptoms in adulthood [5, 6].

DNA methylation is a mechanism of epigenetic regulation, which affects gene transcription. Various environmental factors including stress can alter the DNA methylation pattern of cells [7]. Childhood adversities have been associated with differential DNA methylation of genes involved in neuronal development, cell signaling, inflammation and disease biomarkers by several whole-genome studies [8]. Genome-wide DNA methylation studies in PTSD patients have implicated among others genes involved in immune function [9]. However, the link between DNA methylation changes and complex 
posttraumatic symptoms has not been specifically investigated.

Swiss former indentured child laborers (Verdingkinder) were removed as children from their families by the authorities due to different reasons (poverty, being born out of wedlock) and were placed to live and work on farms. This was a practice applied until the 1950s and many of the Verdingkinder were subjected to childhood trauma and neglect during the indentured labor [10]. We have previously identified differentially methylated genes in elderly former child laborers compared to a control group, which included genes involved in neuronal projections and neuronal development [11].

In the current investigation, we assessed the correlation of genome-wide DNA methylation profiles with complex posttraumatic symptoms according to ICD-11 CPTSD in a group of elderly Swiss former indentured child laborers.

\section{Main text \\ Methods \\ Participants}

31 elderly former indentured child laborers (17 M/14 F) were included in the current study. Mean age $( \pm$ SD) was $76.4( \pm 6.3)$ years. Mean age of indenture $( \pm$ SD) was 4.7 $( \pm 4.5)$ years. Mean duration of indenture $( \pm$ SD) was $11.8( \pm 5)$ years. The participants were part of a larger investigation analyzing mental and physical sequelae in elderly former indentured child laborers [12]. Ethical approval was granted by the Cantonal Ethic Commission of Zurich (KEK-ZH-Nr. 2012-0245). Inclusion criteria for the study were: indentured child labor, upbringing in rural areas of Switzerland, at least 65 years of age, voluntary participation, (Swiss) German speaking. Exclusion criteria were: under 65 years of age, insufficient knowledge of German.

\section{Assessment of complex posttraumatic symptoms}

Complex posttraumatic symptoms were evaluated with the trauma symptom inventory (TSI) [13-15]. TSI is a 100-item self-report instrument, which includes 10 clinical scales to assess multiple complex posttraumatic sequelae dimensions (anxious arousal, depression, anger and irritability, intrusive experiences, defensive avoidance, dissociation, sexual concerns, dysfunctional sexual behavior, impaired self reference and tension reduction behavior), as well as three validity scales and twelve critical items. Items are rated on scales ranging from 0 (never) to 3 (often) depending on how often symptoms occurred in the previous 6 months. The validation of the German version of the TSI was carried out in a group of former indentured child laborers and showed overall good reliability and validity [14].
To assess symptom complexity, TSI scores were dichotomized as previously described [5]. For each of the 10 clinical scales values at least 1.5 standard deviations above the median for all former indentured child laborers included in our project were considered as clinically elevated. The number of clinically elevated TSI scales for each participant were used as an indicator of symptom complexity [5].

\section{DNA isolation, bisulfite conversion and Infinium Illumina 450k chip analysis}

Buccal swabs collection and DNA stabilization was carried out as previously described [11]. Buccal swabs were processed at the "Barts and The London Genome Centre" in the United Kingdom. DNA isolation was performed with the Isohelix buccal DNA isolation kit (Cell Projects Ltd) and purification with the Zymo ZR-96 DNA clean-up kit (Zymo Research Corporation, Irvine, United States) according to the manufacturer's recommendations. DNA concentration was controlled with the Qubit 2.0 Fluorometer (Life Technologies) and integrity with agarose gel electrophoresis. DNA bisulfite conversion was carried out with the EZ DNA Methylation kit (Zymo Research Corporation) according to the manufacturer's recommendations. Bisulfite converted DNA was hybridized to the Infinium Illumina 450k Human DNA methylation chip, which encompasses 485,000 methylation sites per sample [16].

\section{Array analysis}

Analysis was carried out in the R environment (http:// cran.r-project.org) using raw intensity data files [17]. Data import, quality control and normalization were carried out with the minfi Bioconductor package [18]. Probes with detection p-values $>0.01$ in any of the samples were excluded. Background correction and normalization were carried out with the Illumina method implemented in minfi (bg.correct $=$ TRUE, normalize $=$ "controls"). Probes on the Illumina Infinium 450k array assaying single nucleotide polymorphisms (SNPs) as well as non-CpG methylation were filtered out. So were the ones containing SNPs at the investigated CpG site or at a single base extension position. Probes located on the sex chromosomes were also excluded. The minfi preprocessed data were analyzed with the CpGassoc package to assess correlation of DNA methylation profiles with complex posttraumatic symptoms measured by the TSI scales [19]. Age, gender, the estimated proportion of buccal epithelial cells, array and slide were included as covariates in the analysis. The proportion of buccal epithelial cells was estimated according to a previously published protocol [20]. The threshold for statistical significance of the results was set at $5 \times 10^{-7}$ according to a 
previously recommended threshold to account for multiple testing [21].

\section{Results}

DNA methylation profiles of elderly former indentured child laborers were significantly associated $\left(\mathrm{p}<5 \times 10^{-7}\right)$ with complex posttraumatic sequelae in the symptom dimensions dissociation, tension reduction behavior and dysfunctional sexual behavior (Table 1). No significant $\left(\mathrm{p}<5 \times 10^{-7}\right)$ association of DNA methylation patterns were observed for the scales anxious arousal, depression, anger and irritability, intrusive experiences, defensive avoidance, sexual concerns and impaired self reference.

Methylation changes at cg12320221 mapped to the first exon of the gene huntington associated protein 1 (HAP1) correlated significantly and negatively with dissociation symptoms severity $(T$-statistic $=-11.45 ; p$ value $\left.=4.54 \times 10^{-7}\right)$. Positive correlation of DNA methylation with the scale tension reduction behavior was detected for cg12328023, which is located in the body of the gene RAN binding protein 2 (RANBP2; T-statistic $=11.73 ; p$-value $\left.=3.61 \times 10^{-7}\right)$. For the scale dysfunctional sexual behavior positive correlation of DNA methylation was observed for cg20739864 in the $3^{\prime}$-UTR of the gene proteasome subunit alpha 4 (PSMA4; T-statistic $=12.05 ; p$-value $=2.8 \times 10^{-7}$ ).

Finally, association of DNA methylation with the number of clinically elevated TSI scales as an indicator of trauma symptom complexity was investigated. Positive correlation for DNA methylation at cg07225277 located in the body of carnosine synthase 1 (CARNS1) was found $\left(T\right.$-statistic $=13.41 ; p$-value $\left.=1.02 \times 10^{-7}\right)$.

\section{Discussion}

Our pilot investigation as part of a comprehensive psychobiologial research program $[11,12]$ identified DNA methylation alterations associated with the complex posttraumatic symptom domains dissociation, tension reduction behavior and dysfunctional sexual behavior in elderly former indentured child laborers. Experimentwide significant association of DNA methylation modifications with trauma symptom complexity was also observed.
For the dissociation scale differential methylation in HAP1 was identified. HAP1 has been shown to be critically involved in a number of neuronal functions, including neuronal survival, inhibitory synaptic transmission and neurogenesis [22, 23]. Disruption of HAP1 in the early postnatal period in mice has been associated with depressive-like behavior in later life [24].

RANBP2 (with DNA methylation correlated with tension reduction behavior) is involved in SUMOylation, a posttranslational modification with important role in a range of neuronal functions, including neuronal survival and synaptic transmission [25]. PSMA4, methylation in which was associated with dysfunctional sexual behavior, is also involved in posttranslational modifications, since it encodes a subunit of the $20 \mathrm{~S}$ proteasome. The ubiquitin-proteasome system plays an important role in the regulation of memory formation [26].

Correlation of DNA methylation in carnosine synthase 1 (CARNS1, known also as ATPGD1) with trauma complexity was also observed. CARNS1 catalyzes the formation of carnosine and homocarnosine, which are compounds with anti-oxidant properties [27]. Dietary supplementation with carnosine has shown positive effects on cognition on veterans suffering from Gulf War illness [28].

Overall, we detected stronger association of DNA methylation profiles with complex posttraumatic symptoms rather than "classical" PTSD symptoms. DNA methylation alterations were found in genes involved in neuronal function and posttranslational modifications. Proving the relevance of these findings would require their replication in larger study cohorts and after different trauma types.

Our pilot findings imply a correlation of DNA methylation modifications with complex posttraumatic sequelae in elderly individuals exposed to prolonged and complex childhood trauma.

\section{Limitations}

Limitations of our investigation include its cross-sectional design, the relatively small sample size, the use of peripheral tissue (buccal epithelial cells), the lack of data on gene expression patterns for the genes showing alterations in DNA methylation and the use of a CPTSD

Table 1 Differentially methylated CpG sites, which reached experiment-wide significance

\begin{tabular}{llcll}
\hline TSI Scale & CpG site & Chromosome & Gene symbol & p-value \\
\hline Dissociation & cg12320221 & 17 & HAP1 & $4.54 \times 10^{-7}$ \\
Tension reduction behavor & cg12328023 & 2 & RANBP2 & $3.61 \times 10^{-7}$ \\
Dysfunctional sexual behavior & cg20739864 & 15 & PSMA4 & $2.8 \times 10^{-7}$ \\
Number of clinically elevated scales & cg07225277 & 11 & CARNS1 & $1.02 \times 10^{-7}$ \\
\hline
\end{tabular}


assessment that is not fully equivalent to the ICD-11 CPTSD model [see 29]. Although certain tissue specificity in epigenetic patterns exists, evidence that DNA methylation alterations after early life adversity is a system-wide phenomenon has been accumulating, supporting the utility of surrogate peripheral tissues for analysis [30].

\section{Abbreviations}

PTSD: posttraumatic stress disorder; CPTSD: complex posttraumatic stress disorder; HAP1: huntington associated protein 1; RANBP2: RAN binding protein 2; PSMA4: proteasome subunit alpha 4; CARNS1: carnosine synthase 1; ICD-11: International Classification of Diseases-version 11; M: male; F: female SD: standard deviation; TSI: trauma symptom inventory; SNP: single nucleotide polymorphism.

\section{Authors' contributions}

AM, SW and ZM conceived and designed the study with input from EG and TW. ZM, AM, TW, EG and SW were involved in data analysis and interpretation. ZM drafted the manuscript, which was revised by all authors. All authors read and approved the final manuscript.

\section{Author details}

1 Department of Child and Adolescent Psychiatry and Psychotherapy, Psychiatric Hospital, University of Zurich, Zurich, Switzerland. ${ }^{2}$ Department of Psychology, Division of Psychopathology and Clinical Intervention, University of Zurich, Binzmühlerstrasse 14/17, Raum BIN 3 E 14, 8050 Zurich, Switzerland.

${ }^{3}$ Aarhus Institute of Advanced Studies, University of Aarhus, Aarhus, Denmark.

\section{Acknowledgements}

We thank all participants in the current study. We thank the "Barts and The London Genome Centre" for performing the Illumina Infinium 450k DNA methylation arrays experiments.

\section{Competing interests}

The authors declare that they have no competing interests.

\section{Availability of data and materials}

The ethical permission for the study does not include a permission to make underlying patient-specific data publicly available.

\section{Consent for publication}

Not applicable.

\section{Ethics approval and consent to participate}

Approval for the study was obtained by the Cantonal Ethic Commission of Zurich. All participants gave their informed consent to participate.

\section{Funding}

Not applicable.

\section{Publisher's Note}

Springer Nature remains neutral with regard to jurisdictional claims in published maps and institutional affiliations.

Received: 28 March 2017 Accepted: 12 December 2017

\section{References}

1. Briere J, Scott C. Complex trauma in adolescents and adults: effects and treatment. Psychiatr Clin North Am. 2015;38:515-27.

2. Yehuda R, Flory JD, Pratchett LC, Buxbaum J, Ising M, Holsboer F. Putative biological mechanisms for the association between early life adversity and the subsequent development of PTSD. Psychopharmacology. 2010;212:405-17.

3. Marinova Z, Maercker A. Biological correlates of complex posttraumatic stress disorder-state of research and future directions. Eur J Psychotraumatol. 2015:6:25913.

4. Maercker A, Brewin CR, Bryant RA, Cloitre M, Reed GM, van Ommeren M, et al. Proposals for mental disorders specifically associated with stress in the International Classification of Diseases-11. Lancet. 2013;381:1683-5.

5. Briere J, Kaltman S, Green BL. Accumulated childhood trauma and symptom complexity. J Trauma Stress. 2008;21:223-6.

6. Cloitre M, Stolbach BC, Herman JL, van der Kolk B, Pynoos R, Wang J, et al. A developmental approach to complex PTSD: childhood and adult cumulative trauma as predictors of symptom complexity. J Trauma Stress. 2009:22:399-408

7. Booij L, Wang D, Le'vesque ML, Tremblay RE, Szyf M. Looking beyond the DNA sequence: the relevance of DNA methylation processes for the stress_-diathesis model of depression. Phil Trans R Soc B. 2013;368:51.

8. Lutz PE, Almeida D, Fiori LM, Turecki G. Childhood maltreatment and stress-related psychopathology: the epigenetic memory hypothesis. Curr Pharm Des. 2015:21:1413-7.

9. Uddin M, Aiello AE, Wildman DE, Koenen KC, Pawelec G, de Los Santos $\mathrm{R}$, et al. Epigenetic and immune function profiles associated with posttraumatic stress disorder. Proc Natl Acad Sci USA. 2010;107:9470-5.

10. Wohlwend L, Honegger A. Gestohlene Seelen: Verdingkinder in der Schweiz. Frauenfeld: Huber; 2004.

11. Marinova Z, Maercker A, Küffer A, Robinson MD, Wojdacz TK, Walitza S, et al. DNA profiles of elderly individuals subjected to indentured childhood labor and trauma. BMC Med Genet. 2017;18:21.

12. Burri A, Maercker A, Krammer S, Simmen-Janevska K. Childhood trauma and PTSD symptoms increase the risk of cognitive impairment in a sample of former indentured child laborers in old age. PLoS ONE. 2013;8:e57826

13. Briere J. Trauma symptom inventory: professional manual. Lutz: PAR; 1995

14. Krammer S, Simmen-Janevska K, Maercker A. Towards 'complex PTSD': german translation of the Trauma Symptom Inventory (TSI) for the assessment of complex trauma Sequelae. Psychother Psychosom Med Psychol. 2013;63:318-26.

15. Krammer S, Grossenbacher H, Goldstein N, Kaufmann C, Schwenzel A, Soyka M. Validierung der deutschen Übersetzung des revidierten Trauma Symptom Inventory (TSI-2) zur Erfassung komplexer posttraumatischer Belastungssymptomatik. Psychother Psych Med. 2017. https://doi.org/10. 1055/s-0042-120839.

16. Bibikova M, Barnes B, Tsan C, Ho V, Klotzle B, Le JM, et al. High density DNA methylation array with single $\mathrm{CpG}$ site resolution. Genomics. 2011;98:288-95.

17. R Development Core Team. R. A Language and Environment for Statistical Computing. Vienna: R Foundation for Statistical Computing; 2013.

18. Hansen KD, Ayree M, Irizary RA, Jaffe AE, Maksimovic J, Houseman A, et al Package "minfi": Analyze Illumina's 450k methylation arrays. R package version 1.10.2; 2014

19. Barfield RT, Kilaru V, Smith AK, Conneely KN. CpGassoc: an R function for analysis of DNA methylation microarray data. Bioinformatics. 2012:28:1280-1.

20. Eipel M, Mayer F, Arent T, Ferreira MR, Birkhofer C, Gerstenmaier U, et al. Epigenetic age predictions based on buccal swabs are more precise in combination with cell type-specific DNA methylation signatures. Aging (Albany NY). 2016:8:1034-48.

21. Rakyan VK, Down TA, Balding DJ, Beck S. Epigenome-wide association studies for common human diseases. Nat Rev Genet. 2011:12:529-41.

22. Kittler JT, Thomas P, Tretter $V$, Bogdanov YD, Haucke V, Smart TG, et al. Huntingtin-associated protein 1 regulates inhibitory synaptic transmission by modulating gamma-aminobutyric acid type A receptor membrane trafficking. Proc Natl Acad Sci USA. 2004;101:12736-41.

23. Xiang J, Yang H, Zhao T, Sun M, Xu X, Zhou XF, et al. Huntingtin-associated protein 1 regulates postnatal neurogenesis and neurotrophin receptor sorting. J Clin Invest. 2014:124:85-98.

24. Xiang J, Yan S, Li SH, Li XJ. Postnatal loss of hap1 reduces hippocampal neurogenesis and causes adult depressive-like behavior in mice. PLoS Genet. 2015;11:e1005175. 
25. Henley JM, Craig TJ, Wilkinson KA. Neuronal SUMOylation: mechanisms, physiology, and roles in neuronal dysfunction. Physiol Rev. 2014;94:1249-85

26. Jarome TJ, Helmstetter FJ. The ubiquitin-proteasome system as a critical regulator of synaptic plasticity and long-term memory formation. Neurobiol Learn Mem. 2013;105:107-16.

27. Drozak J, Veiga-da-Cunha M, Vertommen D, Stroobant V, Van Schaftingen E. Molecular identification of carnosine synthase as ATP-grasp domaincontaining protein 1 (ATPGD1). J Biol Chem. 2010;285:9346-56.
28. Baraniuk JN, El-Amin S, Corey R, Rayhan R, Timbol C. Carnosine treatment for gulf war illness: a randomized controlled trial. Glob J Health Sci. 2013;5:69-81.

29. Karatzias T, Shevlin M, Fyvie C, Hyland P, Efthymiadou E, Wilson D, et al. Evidence of distinct profiles of Posttraumatic Stress Disorder (PTSD) and Complex Posttraumatic Stress Disorder (CPTSD) based on the new ICD-11 Trauma Questionnaire (ICD-TQ). J Affect Dis. 2017:207:181-7.

30. Szyf M, Bick J. DNA methylation: a mechanism for embedding early life experiences in the genome. Child Dev. 2013;84:49-57.

\section{Submit your next manuscript to BioMed Central and we will help you at every step:}

- We accept pre-submission inquiries

- Our selector tool helps you to find the most relevant journal

- We provide round the clock customer support

- Convenient online submission

- Thorough peer review

- Inclusion in PubMed and all major indexing services

- Maximum visibility for your research

Submit your manuscript at www.biomedcentral com/submit 